\title{
A Modest Proposal: Field Monitoring and Measurements Education
}

\author{
Vijaya KA Gopu ${ }^{1}$, Ayman Okeil ${ }^{2}$ and Roger K Seals ${ }^{3 *}$ \\ ${ }^{1}$ Professor of Civil Engineering at the University of Louisiana at Lafayette and the Associate Director for External Programs, Louisiana Transportation Research \\ Center \\ ${ }^{2}$ Professor of Civil and Environmental Engineering, Louisiana State University \\ ${ }^{3}$ Professor Emeritus of Civil and Environmental Engineering, Louisiana State University
}

*Corresponding author: Roger K Seals, Professor Emeritus of Civil and Environmental Engineering, Louisiana State University, USA.

Received Date: August 14, 2019

Published Date: August 21, 2019

\section{Opinion}

We propose that undergraduate curricula reform efforts be undertaken to incorporate Field Monitoring and Measurements (FMM) content in the undergraduate civil and environmental (CEE) engineering curriculum. While CEE undergraduate curricula generally incorporate laboratory courses in such topics as material testing, fluid mechanics, and geotechnical engineering, among others, the subject matter is often limited to either an experimental demonstration of theoretical principles or to conducting standard laboratory tests. Field measurements and monitoring techniques and practices may be touched upon but are rarely addressed in any depth. While the content of traditional laboratory courses and practices still have relevance and merit in the preparation of CEE professionals, we assert that there is a growing recognition of the importance and prevalence of FMM in current and future engineering practice. Thus, some undergraduate preparation in the fundamentals and applications of FMM in CEE practice is warranted. Our proposal is informed by the results of two surveys of CEE professionals (one directed principally but not exclusively at practicing structural engineers and one directed exclusively to geotechnical engineers)- the former survey conducted at the local level and the latter conducted at the national level. The identical surveys addressed three essential questions: (1) the current perceived importance of FMM; (2) the future perceived importance of FMM; and (3) the perceived enhancement of the undergraduate CEE curriculum with the addition of FMM education. Only $9 \%$ of the CEE respondents and $8 \%$ of the geotechnical engineering respondents in the respective surveys reported that they had any structured FMM education (a formal course or applicable content in one or more courses) at the undergraduate level. Relative to the current importance of FMM practice, $62 \%$ of the CEE and $92 \%$ of the geotechnical engineering respondents judged current FMM practice to be of significant or extreme importance while $86 \%$ and $89 \%$ of the CEE and geotechnical engineering respondents, respectively, judged the future importance to be of significant or extreme importance. Further, $61 \%$ of the geotechnical engineering and $47 \%$ of the CEE respondents concluded that incorporating FMM education into the undergraduate CEE curriculum would provide a significant or extreme enhancement to the CEE curriculum. In our judgment, these results support both the importance and need for FMM education at the CEE undergraduate level. In the openended response opportunity provided in the surveys, several of the respondents expressed concern over incorporating FMM education in an already packed curriculum.

Acknowledging the concern voiced by some of the survey respondents as well as our own experience, the authors undertook a National Science Foundation- supported pilot project to determine the viability of introducing FMM content into the current CEE curriculum recognizing the curricula constraints and the barriers faculty face in such an endeavor. The project focused on developing, implementing and disseminating an education model for Structural Health Monitoring (SHM) within the required structural analysis and design course sequence found in most CEE undergraduate curricula. The education pedagogy adopted for the SHM content was student-centered, active learning with the stated goal: Within the constraints of the civil engineering curriculum, the goal of SHM education to be achieved via the SHM 
Education Unit is to: 1) raise awareness; 2) stimulate interest; 3) identify resources; and 4) provide a basic understanding of the fundamentals and applications of Structural Health Monitoring (SHM) within the core structural engineering courses as an initial preparation of graduates for relevant professional practice and/ or possible advanced studies about SHM. The SHM Education Unit ultimately developed, implemented and evaluated at six institutions encompassed two subunits- one devoted to SHM fundamentals and one devoted to SHM applications including a laboratory-scale demonstration of SHM technology and monitoring. Each subunit consists of four education modules which the students review on their own, take a readiness test to demonstrate their readiness to engage in a classroom discussion of the content and, finally, actually participating in a faculty-managed but student-focused discussion sessions extending over two 50-minute classes (Figure 1).

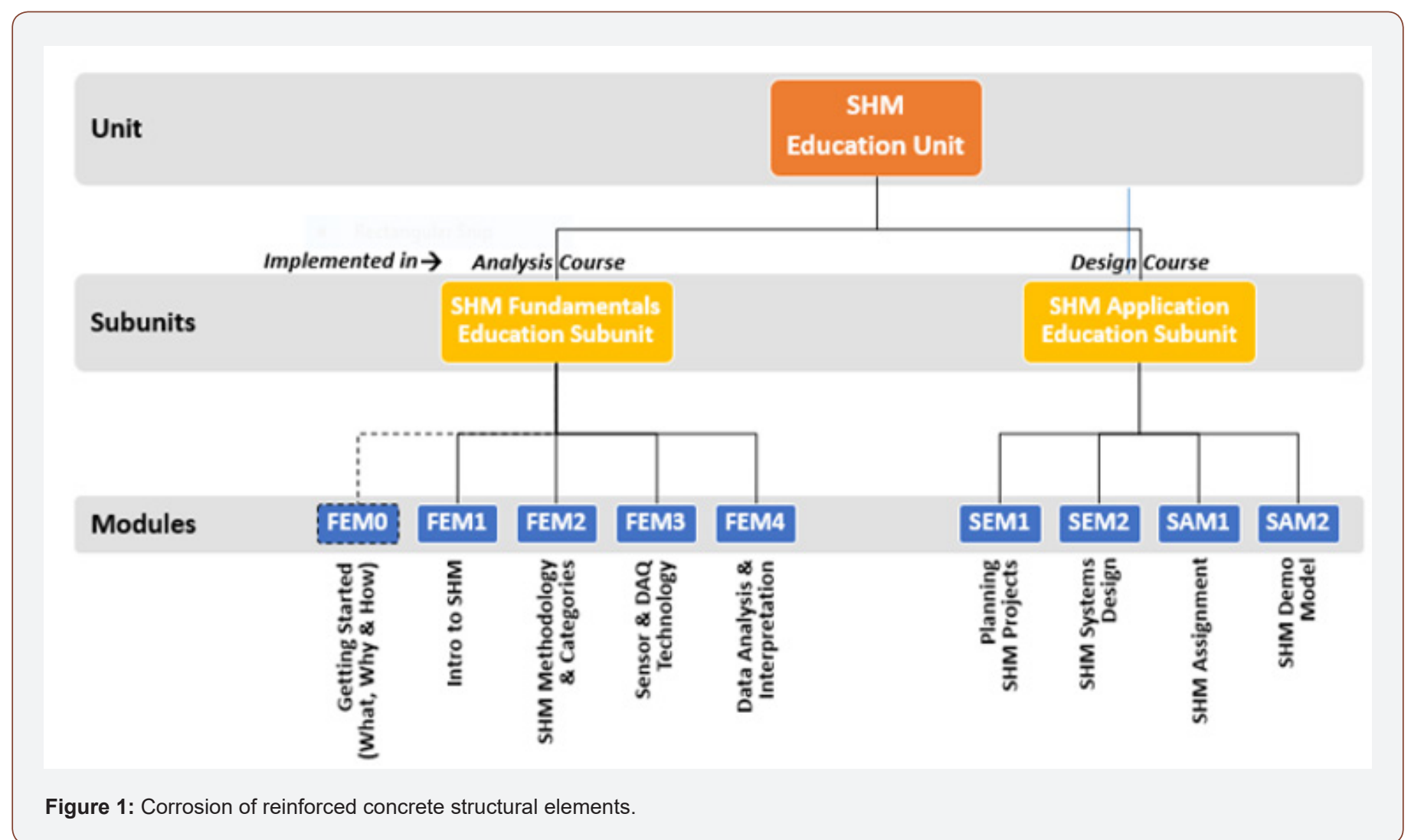

Having developed, implemented, evaluated and revised the SHM Education Unit, we are now in the process of developing an outreach program to introduce potential adopters to the Unit and the comprehensive set of available student education and faculty instruction resources. These resources can be previewed at the FMM Web Portal (www.ltrc.lsu.edu/fmme/). Another important feature of this project is our intent to establish a SHM Faculty Learning Community whose members will contribute to the continued improvement and enhancement of the Unit. Rather than insisting that faculty implement the Unit as developed, we encourage adaptation and innovation but with one proviso; that is, they share their contributions with other users via the bulletin board provided on the Web Portal. In the future, we hope to initiate a comprehensive project in collaboration with faculty from other institutions to extend the SHM Education Unit model and pedagogy to other CEE sub-disciplines.

\section{Acknowledgment}

None.

\section{Conflict of Interest}

No conflict of interest. 